\title{
Construyendo un discurso audiovisual a partir del conflicto: el uso de fotoanimaciones como recurso para interrogar la realidad
}

\section{Constructing an audiovisual discourse based on conflict: the use of photoanimations as a resource for examining reality}

\author{
Xana Morales-Caruncho \\ Universidad de Granada. \\ contacto@xanamorales.com \\ Pedro D. Chacón-Gordillo \\ Universidad de Granada. \\ pchacon@ugr.es
}

Recibido: 17 de agosto de 2012

Aprobado: 13 de diciembre de 2012

\begin{abstract}
Resumen
Aprovechando el proceso de rebeldía característico de la etapa adolescente esta investigación pone en práctica un proyecto con intencionalidad investigadora fundamentado en la idea de que es posible aprovechar el conflicto interior vivido por los jóvenes para la creación de una serie de narraciones audiovisuales. Este proyecto nos permitirá averiguar cuáles son los problemas que afectan a la juventud contemporánea y ayudará a docentes e investigadores a aproximarse un poco más a ese universo juvenil del que forman parte. Los resultados de esta experiencia, que son visibles a través de la red en la dirección http://narrativasfotoanimadas.blogspot.com.es constituyen una clara prueba de que un ejercicio de autorreflexión dentro del aula invita no solo a los jóvenes a defender una identidad propia a través de sus discursos, sino también a los docentes e investigadores a conocer desde una perspectiva más cercana la realidad adolescente actual.
\end{abstract}

Palabras Clave: educación artística, adolescencia, fotoanimaciones, creación audiovisual, conflicto.

Morales-Caruncho, X., Chacón-Gordillo, P.D. (2013): Construyendo un discurso audiovisual a partir del conflicto: el uso de fotoanimaciones como recurso para interrogar la realidad. Arte, Individuo y Sociedad, 25(3) 406-423

\begin{abstract}
By using the process of rebelliousness that is characteristic of the teenage stage, this investigation puts in practice a project with a research purpose based on the idea that it is possible to make use of the internal conflict experienced by young people to create a series of audiovisual stories. This project enables us to determine the problems which affect today's youth and to help teachers and researchers gain a greater understanding of this juvenile universe which they are involved in. The results of this experience, which can be seen on the net at the address http://narrativasfotoanimadas.blogspot.com. es offer clear proof that an exercise of self-reflection within the classroom not only invites young people to defend their own identity through their speech, but also invites teachers and researchers to gain a greater insight into the current teenage reality.
\end{abstract}

Key Words: art education, adolescence, photoanimations, audiovisual creation, conflict. 
Morales-Caruncho, X., Chacón-Gordillo, P.D. (2013): Constructing an audiovisual discourse based on conflict: the use of photoanimations as a resource for examining reality. Arte, Individuo y Sociedad, $25(3)$ 406-423

Sumario: 1. Introducción, 2. Primera etapa: La adolescencia como un proceso de autonomía a través del conflicto, 2.1. Cómo aprovechar el conflicto para la construcción de un discurso: El/la adolescente como héroe o heroína de su propia historia, 3. Segunda etapa: Educación audiovisual, un nuevo tipo de alfabetización, 4. Tercera etapa: Las fotoanimaciones como recurso para interrogar la realidad, 4.1. Sistemática empleada en el análisis de las fotoanimaciones, 5. Cuarte etapa: Contexto de investigación y puesta en marcha, 5.1. Creación de fotoanimaciones, 5.2. Análisis de fotoanimaciones: Resultados, 6. Conclusiones. Referencias.

\section{Introducción}

Este proyecto de investigación empírico nace de la idea de ahondar en la realidad y las preocupaciones de los adolescentes contemporáneos. Para ello se incita a un grupo de 23 alumnos/as de $1^{\circ}$ de Bachillerato a realizar una serie de narraciones audiovisuales a través de la técnica del stop motion que a partir de ahora llamaremos "fotoanimaciones". Cada una de estas creaciones tiene como fundamento narrativo la denuncia y proposición de un cambio y su intención final es que los estudiantes se vean comprometidos a reflexionar acerca de aquellas cuestiones que les preocupan y afectan de forma directa. De esta forma se pretende que sus frustraciones se conviertan en algo constructivo que les permita conocerse más a sí mismos y al mundo que les rodea a través de la puesta en práctica de diferentes procesos como la observación, el diálogo, la creación propia y la adquisición de autonomía y capacidad crítica.

Como forma de evidenciar nuestras consideraciones previas, el consiguiente proceso de investigación dentro del aula y las conclusiones obtenidas hemos dividido esta exposición en una serie de etapas o fases:

- Primera etapa: Aclaración del concepto de "adolescencia" y presentación del discurso audiovisual como forma de indagar en la mente adolescente.

- Segunda etapa: Disertación sobre la necesidad de una alfabetización audiovisual llevada a cabo desde la escuela — ya sea esta primaria, secundaria o postobligatoria-.

- Tercera etapa: Explicación del concepto "fotoanimación" y esclarecimiento de su utilidad como herramienta de indagación.

- Cuarta etapa: Relato de la puesta en práctica de la parte empírica de la investigación, describiendo el trabajo realizado dentro del aula y los resultados obtenidos. Finalmente, exposición de las conclusiones obtenidas.

Esta investigación emerge, además, de una serie de objetivos:

- Conocer algunos de los problemas actuales que preocupan a los adolescentes.

- Observar estos problemas desde el punto de vista del propio alumnado.

- Favorecer la reflexión del alumnado sobre aquellos temas que les preocupan y la búsqueda de posibles soluciones. 
- Estudiar la capacidad tanto constructiva-formal como narrativo-discursiva del alumnado a través del medio audiovisual.

- Realización de una comparativa entre el uso de un tipo de narrativa clásica y la utilización de un discurso de carácter más contemporáneo o postmoderno por parte del alumnado.

Con respecto a la metodología debemos hablar de un modelo cualitativo basado en el estudio de caso, y es que este proyecto se lleva a cabo dentro de una de las muchas aulas de $1^{\circ}$ de Bachillerato que existen en nuestro país, pero tratando, a su vez de, llegar al conocimiento de un asunto más amplio como son los problemas que preocupan a los adolescentes en la actualidad. Asimismo, dentro de este estudio de caso se decide combinar el uso de diferentes técnicas de indagación divididas en dos grandes grupos:

\section{Grupo 1: Recursos para observar y comprender la realidad:}

Observación directa y participante.

Notas de campo.

Fotografías del proceso de trabajo.

\section{Grupo 2: Recursos para interrogar y transformar la realidad}

Fotoanimaciones.

Entrevistas.

Documentos del desarrollo creativo de las fotoanimaciones: story line, escaleta y story board.

Con respecto a las fuentes de este trabajo estas proceden, básicamente, de tres áreas del conocimiento: la educación artística — como esfera principal en la que se enmarca nuestra investigación-, la psicosociología — que nos ha servido, por ejemplo, a la hora de definir el concepto de adolescencia-, y el ámbito audiovisual o cinematográfico - a través del cual concretamos el uso de las fotoanimaciones como herramientas de indagación-. Es en las tres primeras etapas de nuestra investigación cuando más recurrimos al conocimiento y experiencias de otros autores y expertos de estos ámbitos pues es ahí cuando perfilamos tanto el estado de la cuestión de nuestro proyecto como nuestra metodología.

Para terminar esta introducción sólo queda señalar que las conclusiones de nuestro proyecto nos permiten afirmar que la mayor parte de nuestros objetivos quedan resueltos al final de nuestro trabajo pues, además de llegar al conocimiento de algunos de los problemas que preocupan al adolescente contemporáneo, los discursos audiovisuales realizados por los propios alumnos nos han permitido acercarnos algo más a su forma de ver la realidad y evaluar tanto su capacidad crítica — desde un punto de vista psicosociológico - como su solvencia constructivo-formal y narrativodiscursiva —en lo que se refiere a la creación artística-.

Pasamos entonces ya a exponer de cada una de las etapas de esta investigación de una manera más profunda y pormenorizada. 


\section{Primera etapa: La adolescencia como un proceso de autonomía a través del conflicto}

Partiendo de que la palabra adolescencia procede del latín "adolecere", que significa "crecer" o "desarrollarse hacia la madurez" podemos afirmar que la adolescencia es una etapa del crecimiento humano en la que tiene lugar un desarrollo tanto biológico o fisiológico como psicológico y social. Pero lo que interesa a esta investigación es el enfoque psicosocial del término. A este respecto, determinados autores (Kett, 1977; Hopkins 1987; Palacios, 1991) consideran la delimitación de esta etapa de la madurez como un producto de las sociedades occidentales acomodadas, y es que, en términos específicos, en épocas anteriores a la industrialización occidental "no existía una cultura adolescente, ni la adolescencia era percibida como un estadio particular del desarrollo" (Palacios, 1991, p. 300). Sin embargo, es evidente que actualmente podemos hablar de una cultura adolescente absolutamente asentada, que, aunque ecléctica en tendencias, ideologías y pensamientos, comparte unos rasgos comunes que le permiten autoafirmarse como cultura propia (Aguirre, 1994).

Pero, ¿cuáles son las características de esta etapa? Erikson (1992) la definió como la etapa en la que el ser humano conquista la "autonomía", describiéndola como la adquisición del sentido de autocontrol e iniciativa en los jóvenes. Pero no fue el único que señaló la obtención de una mayor independencia como la característica clave de esta etapa. Más bien al contrario, son muchos los psicólogos que coinciden en esto, como Kohlberg (1992) que se refirió a la adolescencia como el "nivel postconvencional o autónomo" del desarrollo humano. Asimismo, Loevinger (1990) denominó "autoconciencia" a esta etapa y Kegan (1982) se refirió a ella como "etapa de crecimiento y pérdida del equilibrio imperial". Así pues, la adolescencia es una transformación, un proceso de cambio que implica la transición de una etapa del crecimiento a la siguiente. "Mientras el adulto parece el resultado de un proceso de crecimiento, la adolescencia se considera como un proceso [en sí mismo], como el paso de un estadio a otro" (Rocheblave-Spenlé, 1975, p. 16).

Además, para que tenga lugar es necesario que se produzca un hecho determinado, que se corresponde con la pérdida o debilitación de los referentes de autoridad que habían sido piezas claves durante la niñez. Y es que la autonomía suele lograrse a través de un conflicto manifestado por la desobediencia que se puede materializar en un desafío a los padres o a la autoridad en general (Erikson, 1992). En contra de la creencia popular que entiende que la desobediencia juvenil es algo puramente negativo, lo cierto es que el ser humano necesita rebelarse contra lo establecido en un determinado momento de su vida, requiere de esa rebeldía para evolucionar, adquirir independencia y formarse sus propios juicios de valor, pues sólo de esta forma puede convertirse en un individuo autónomo.

\subsection{Cómo aprovechar el conflicto para la construcción de un discurso: EV/la adolescente como héroe o heroína de su propia historia}

Partiendo de estas ideas nace este proyecto investigador, que tratará de utilizar el proceso de rebeldía característico de esta etapa como algo constructivo dentro 
del aula. Para ello, y como ya aclaramos en la introducción, realizamos una serie de "fotoanimaciones" con un grupo de 23 alumnos de $1^{\circ}$ de Bachillerato.

Pero, ¿por qué utilizar el audiovisual como forma de indagar en la preocupación de los estudiantes? La respuesta es que "lo audiovisual, en lo que tiene de fenómeno comunicativo, informa, persuade y entretiene con unos recursos propios y específicos. Esos recursos específicos no se agotan en lo material de las imágenes y sonidos. Lo fundamental es su carácter de discurso" (Montero Díaz, 2009, p. 9). Lo audiovisual es esencialmente narrativo, se basa en la construcción de un argumento, en la transmisión de una idea, y como tal, cuenta con una estructura propia que se nutre de estructuras narrativas clásicas cuyo origen está en los mitos griegos y que eran definidas por primera vez en el siglo IV a.C., cuando Aristóteles escribió La poética (2009).

Hemos quedado en que la tragedia es imitación de una acción completa y entera, de cierta magnitud. Es entero lo que tiene principio, medio y fin. Principio es lo que no sigue necesariamente a otra cosa, sino que otra le sigue por naturaleza en el ser o en el devenir. Fin, por el contrario, es lo que por naturaleza sigue a otra cosa, o necesariamente o las más de las veces, y no es seguido por ninguna otra. Medio, lo que no sólo sigue a una cosa, sino que es seguido por otra. Es pues, necesario, que las fábulas bien construidas no comiencen por cualquier punto ni terminen en otro cualquiera, sino que además se atengan a las normas dichas. (Aristóteles, [S. IV a.C.] 2009, p. 152).

Pero uno de los autores que mejor reinterpreta esta estructura narrativa adaptándola al ámbito audiovisual es Vogler en El viaje del escritor (2002). Vogler, que se inspira en el patrón narrativo de las leyendas y cuentos populares esbozado por Campell en 1949, afirma que "todas las historias están compuestas por unos pocos elementos estructurales que encontramos en los mitos universales, los cuentos de hadas y los sueños" (Vogler, 2002, p. 31).

Según la ordenación que este autor propone de los acontecimientos, el héroe de la historia o protagonista - que constituye el centro de la acción-recorre un camino durante el desarrollo de la misma. Este camino se divide en etapas, que se agrupan dentro del planteamiento, nudo y desenlace de la narración. Durante el planteamiento o primer acto de la historia las etapas son las siguientes:
1. El mundo ordinario
2. La llamada de la aventura
3. El rechazo de la llamada
4. El encuentro con el mentor
5. La travesía del primer umbral (Vogler, 2002, p 46).

En este lapso de tiempo al protagonista se le plantea un problema determinado en su vida cotidiana, un conflicto. Primero no quiere verlo, pero seguidamente algo le empuja a reaccionar, adentrándolo en la historia y dando paso al nudo de la trama o segundo acto, que posee sus propias etapas. 
6. Las pruebas, los aliados, los enemigos

7. La aproximación a la caverna más profunda

8. La odisea (el calvario) o la prueba definitiva

9. La recompensa (Vogler, 2002, p. 46).

En el nudo de la trama se desarrollan las acciones de mayor importancia para el protagonista. Éste ha decidido enfrentarse al problema, lo que le supondrá tener que superar una serie de obstáculos. Durante este proceso se encontrará con otros personajes que le ayudarán o le pondrán dificultades. Finalmente, se enfrentará a una prueba u obstáculo definitivo, el más importante de todos, superado el cual se habrá solucionado el conflicto y entraremos ya en el tercer acto o desenlace.

10. El camino de regreso

11. La resurrección

12. El retorno con el elixir (Vogler, 2002, p. 46).

En el desenlace la intensidad de las acciones y su emoción disminuyen. El héroe vuelve a su vida cotidiana, pero esta vuelta a la normalidad está marcada por el hecho de haber conseguido sus objetivos. El héroe ha cambiado, ya nunca será el mismo; ha superado un reto y ha experimentado un proceso de aprendizaje. Este cambio evolutivo es lo que se conoce como "arco de transformación del personaje".

Podría decirse que el proceso que experimenta el protagonista de cualquier historia - materializada en un soporte audiovisual o no- es similar al que sufre el ser humano durante la adolescencia. Ambos se encuentran con un conflicto, ambos se enfrentan a él y ambos acaban extrayendo una determinada enseñanza de la resolución de los acontecimientos. La importancia del término conflicto dentro de esta investigación resulta, por lo tanto, de vital importancia debido a dos razones fundamentales:

1. Su presencia dentro del desarrollo psicosocial del adolescente. Según autores como Rivero la indisciplina y el cuestionamiento de la autoridad son rasgos clave de la etapa adolescente porque "la adolescencia es la etapa [...] donde se afronta la cuestión psicológica de la identidad" (2006, p. 34). Los jóvenes dejan de fijarse en la aprobación de los demás y de adaptarse al "statu quo" para pasar a conformar sus propios principios morales (Kohlberg, 1992).

2. Su definición desde un punto de vista narrativo. Según Field, profesor en Harvard y autor de uno de los manuales sobre escritura cinematográfica más importantes, el conflicto es "la esencia de cualquier drama" (1995, p. 15). Los conflictos dan lugar a un cambio en la situación vital de un personaje, se oponen a su voluntad y su deseo y, consecuentemente, hacen que éste se revele a ellos durante el desarrollo de la historia (McKee, 2004).En definitiva, si realizamos un esquema de lo que podría ser el desarrollo humano en base a lo recogido hasta el momento y lo comparamos con el paradigma narrativo que presenta Field (1995) en su obra El libro del guión la similitud se hace evidente. 
A. Posible esquema del desarrollo humano:

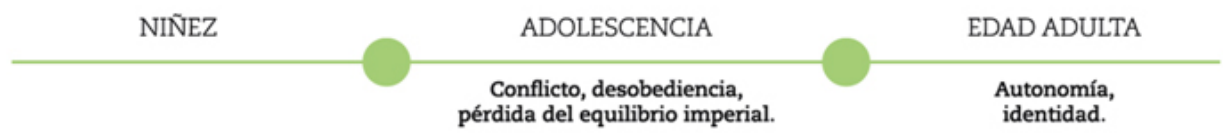

B. Paradigma de la estructura dramática (Field, 1995: 13):

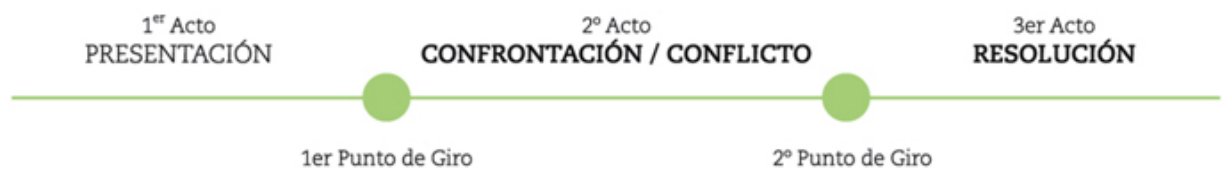

Figura 1. Esquema comparativo entre una posible representación del desarrollo humano y el paradigma clásico de la estructura dramática.

Aunque lo cierto es que hoy en día son numerosas las rupturas que se producen con respecto a este paradigma clásico dentro de la narración audiovisual. Tendencias como el videoarte o las corrientes cinematográficas artísticas - expresionismo alemán, surrealismo francés, neorrealismo italiano, etc.- no poseen estructuras narrativas claramente marcadas, pero la verdad es que los elementos más básicos continúan presentes incluso en estas nuevas formas. Eso es lo que defienden, al menos, autores como Bordwell y Thompson (1995) o McKee (2004), que denominan a estas estructuras "sistemas formales no narrativos" o "antitramas", respectivamente.

Desde este punto de vista, cualquier tipo de expresión humana contiene, por anárquica que parezca, determinados elementos axiomáticos, como la presentación de una determinada idea, la presencia de un conflicto que se debe resolver y la extracción final de una enseñanza que puede afectar tanto al protagonista de la acción en el caso de una película de cine clásico, como al propio espectador si se trata de una obra videoartística.

En definitiva, para la puesta en marcha de este proyecto partimos de la creencia de que toda expresión del pensamiento humano no deja de ser un viaje, un proceso o una evolución, similar a la que experimenta el propio ser humano durante la etapa adolescente. Es por eso que escogemos la narrativa audiovisual como forma de comprensión de la juventud. ¿Qué mejor que narrar cuando los propios conflictos vitales de los adolescentes podrían convertirse en una narración?

Por esto mismo en este proyecto los héroes y heroínas de cada historia son los propios alumnos/as que se tienen que enfrentar, aplicando la técnica del stop motion, a sus particulares conflictos, tratando de resolverlos y llegando a adquirir un aprendizaje final. 


\section{Segunda etapa: Educación audiovisual, un nuevo tipo de alfabetización}

Aclarada la primera razón que nos lleva como investigadores a adoptar el audiovisual como soporte artístico, pasamos a señalar el segundo motivo por el que realizamos esta elección, que está directamente relacionado con la educación.

La inclusión del audiovisual en el ámbito de lo educativo no es una idea reciente. Desde la segunda mitad de los años setenta multitud de investigadores han asumido este terreno como un campo preferente de investigación. Uno de los primeros fue Decaigny (1978), quien realiza la siguiente declaración:

El método audiovisual debe ser racionalmente integrado a la comunicación pedagógica, tal como el impreso o la expresión verbal. (Decaigny, 1978, p. 1).

$\mathrm{Y}$ es que ya no es posible negar que "las imágenes de los medios audiovisuales proporcionan un material extraordinario para educar visual y plásticamente a nuestro alumnado" (Roldán, 2003, p. 350) ofreciéndoles gran cantidad de información visual que resulta muy útil para la formación artística y estética. Pero, yendo incluso más allá de su pura función como medio educativo para la expresión y la creatividad, el medio audiovisual destaca por su función como medio sociocultural (Escaño, 2002), y es que "de todas las artes el cine [y, por extensión, el audiovisual] es el menos aislado de la realidad social" (Aumont, 2004).

Hoy en día soportes como el televisivo o el digital están plagados de discursos que nos construyen como seres humanos, modelando nuestras conciencias sin que seamos apenas conscientes de ello (Maeso, 2008). Esta opinión, compartida por numerosos expertos (Gubern, 1974; Rocher, 1985; González, 1994; Arnett, 1995; Sánchez, 1997; Ferrés, 2000; Huertas, 2002; Padilla, 2002; etc) deja claro que es necesario que los jóvenes adquieran una verdadera compresión de cómo opera el poder dentro de estos aparatos culturales, pues sólo así podrán juzgar los discursos a los que están expuestos de una manera crítica (Giroux, 2003).

Este proyecto se fundamenta en la creencia de que las instituciones educativas necesitan redefinir sus currículos adaptándose a una concepción posmoderna de la cultura, dentro de la cual son necesarias nuevas formas de alfabetización relacionadas con los medios audiovisuales (Giroux, 2003). En base a esto este proyecto de fomentar en las instituciones educativas la comprensión crítica de las imágenes que se consumen y lo hace a través de la puesta en marcha de un proceso de construcción de objetos artísticos (Martínez, 2002). Se intenta conseguir que el alumnado experimente lo que significa ser el productor de un discurso cultural sobrepasando el acto de consumo para llegar a la autoproducción de una información y expresión propia (Giroux, 2003).

\section{Tercera etapa: Las fotoanimaciones como recurso para interrogar la realidad}

Señalada la importancia de incluir la alfabetización audiovisual como un contenido curricular en la enseñanza la pregunta es, ¿por qué consideramos que las fotoanimaciones ${ }^{1}$, como productos audiovisuales concretos, son un recurso idóneo para que el alumnado - y por extensión el investigador — interrogue la realidad?

Realizar una fotoanimación conlleva para el alumno/a la puesta en marcha un proceso de construcción y autorreflexión. Esto hace que, como elemento de análisis, 
estos productos audiovisuales sean de gran interés, pues contienen fragmentos ya filtrados del pensamiento de un estudiante. Cuando observamos una fotoanimación finalizada por parte del alumno/a, estamos también visualizando el resultado de un proceso en el que ya ha priorizado la información principal por encima de la secundaria realizando con ello un esfuerzo discursivo que refleja la forma que su creador tiene de ver un problema determinado. Como dijo Jean Mitry, el lenguaje de la imagen dinámica es "una forma de organizar, construir y comunicar pensamientos" (1978: 48) y, por este motivo, las fotoanimaciones son herramientas idóneas para conocer los de los propios estudiantes.

Otra razón por la que consideramos válido el uso de fotoanimaciones como herramienta de investigación se basa en el hecho de que este tipo de lenguaje audiovisual, por su forma ágil, directa y explícita similar a la de los cortometrajes, resulta especialmente cercana a los lenguajes audiovisuales que consumen hoy en día los adolescentes. En la actualidad, los sitios web con contenidos audiovisuales en Internet se han multiplicado, llegándose a producir una revolución que "ha arrebatado el poder audiovisual a las grandes empresas y grupos comunicativos, generando modos alternativos de ver" (Bartolomé, 2008: 31). Los jóvenes, habituados a estas nuevas tecnologías, son los mayores consumidores de contenidos audiovisuales digitales, por lo que les resultan cercanos a su propia realidad. Asimismo, la posibilidad de construir o elaborar por sí mismos un discurso similar a los que suelen consumir hace que se motiven por llevar a cabo la actividad, por lo que los resultados son más satisfactorios y, sobretodo, más cercanos a la realidad de sus pensamientos.

El audiovisual ha sido y es una herramienta de insuperable valor educativo [...] La facilidad con que las generaciones jóvenes analizan y comprenden el lenguaje cinematográfico hace posible que [gracias al uso de esta herramienta en el aula] seamos capaces de sacar a la luz grandes contenidos de alcance formativo. (De la Llave, 2009, pp. 62-63).

\section{1 Sistemática empleada en el análisis de las fotoanimaciones}

Pasamos a definir los aspectos que esta investigación analiza en cada fotoanimación y que se pueden agrupar bajo dos grandes categorías: los aspectos discursivos y los aspectos formales. El análisis de los primeros se orienta a estudiar tanto el modo de construcción de la narración como el mensaje principal que comunica, tratando de llegar a entender con la mayor profundidad posible todos los aspectos de la idea que el adolescente quiere transmitir. Por otro lado, el análisis de los aspectos formales trata de ahondar en la forma de representación de esos problemas desde un punto de vista estético y visual. Es un esfuerzo por llegar al conocimiento tanto de la "intención" como de la "forma" de cada una de las creaciones audiovisuales realizadas (Eisner, 1995). De esta manera es posible tanto identificar algunos de los problemas que preocupan a los adolescentes, como estudiar la capacidad constructivo-formal y narrativo-discursiva del alumnado.

Dicho esto, pasamos a enumerar los aspectos discursivos a estudiar en cada una de las fotoanimaciones realizadas por el alumnado. 
En primer lugar, definiremos cual es la "idea controladora" de cada relato. Este término, acuñado por McKee (2004), se refiere a la forma más pura del significado narrativo, es decir, al mensaje más esencial que la narración pretende transmitir.

En segundo lugar, trataremos de esclarecer cual constituye lo que Tobias (2004) denomina "el motivo dominante" de la narración, que se refiere al tipo de trama utilizada para ejecutar la historia. Según este autor existen dos tipos de tramas básicas en cualquier relato de tipo audiovisual: por un lado las "físicas" y por otro las "psicológicas". Mientras las tramas psicológicas examinan "el interior de la naturaleza humana y las relaciones entre las personas" (Tobias, 2004, p. 55) las tramas físicas se basan más en la resolución de un problema o enigma que en los propios personajes, siendo la acción lo verdaderamente importante. Basándonos en esta clasificación realizada por Tobias (2004) podría hacerse una tipificación de los posibles tipos de tramas orientada al análisis de las fotoanimaciones.

\section{Tramas físicas}

Búsqueda: Esta trama se basa en la búsqueda que efectúa el protagonista de algo que espera o desea cambiará su vida de manera significativa (Tobias, 2004, p.81).

Enigma: Este tipo de tramas sugieren un significado oculto, es por eso que es necesario analizar la narración en busca de pistas que nos aporten la solución (Tobias, 2004, p. 137).

Venganza: En el centro de esta historia se halla el protagonista, quien por lo habitual es una buena persona obligada a realizar una venganza por su cuenta una vez que la ley no puede hacer nada (Tobias, 2004: 124).

\section{Tramas psicológicas}

Transformación: La trama de la transformación trata acerca del proceso de cambio que sufre el protagonista cuando experimenta una de las muchas etapas de la vida, centrándose, además, en la naturaleza de ese cambio y en cómo este afecta al protagonista (Tobias, 2004, pp. 179-180).

El desvalido: En la trama del desvalido las fuerzas no están igualadas. El protagonista se halla en desventaja y ha de hacer frente a obstáculos insuperables (Tobias, 2004, p. 155).

Tentación: La historia de la tentación es la historia de la fragilidad humana [...] cuando se sufre una tentación, hay varias fuerzas en conflicto en nuestro interior (Tobias, 2004, p.163).

Esta clasificación, aplicada a las creaciones realizadas por los estudiantes, nos puede ayudar a saber el punto de vista que éstos tienen sobre el problema reflejado en cada una de las fotoanimaciones. Por ejemplo, si el relato elaborado se basa en la venganza, es posible intuir la forma en la que el adolescente se enfrentaría a un determinado problema. Por el contrario, si éste se basa en la transformación 
del personaje protagonista, podría llegarse a la conclusión de que el alumno/a está construyendo un relato acerca de la madurez. Al mismo tiempo, cada fotoanimación no tiene por qué corresponderse con una única trama, pudiendo combinar en una misma historia diferentes aspectos o diferentes formas de tratamiento. De esta forma, un relato sobre la tentación se puede convertir, si el protagonista consigue vencerla, en un relato acerca de la transformación del personaje.

Por otro lado, junto al análisis de las tramas, se realiza también un análisis de las estructuras narrativas. Este aspecto trata de distinguir, a grandes rasgos, si la forma narrativa de la historia se corresponde más con la estructura clásica enunciada por Aristóteles en el siglo IV a. C.- - asociada al conservador paradigma de: principio, medio y fin-, o, por el contrario, responde más a una tipología antinarrativa o no formal similar a las corrientes de cine artístico o al videoarte.

El tercer aspecto a observar en el análisis de las fotoanimaciones es el contexto de desarrollo de la historia y los personajes que en ella aparecen. Con esta información pretendemos llegar al conocimiento de los entornos en los que se desarrollan los conflictos que afectan a los adolescentes actuales, las personas que entran en juego en dichos conflictos y las fuerzas antagonistas a las que se enfrentan para resolverlos.

Finalmente, el último y quizás más importante aspecto narrativo en el que nos detendremos es la forma en la que los adolescentes realizan la resolución del problema planteado, y es que uno de los requisitos de partida de cada narración es plantear, además de una denuncia determinada, una solución a la misma. Con ello, la intención es averiguar cómo los adolescentes se enfrentan a los problemas que se les presentan, y para ello se parte de la idea de que estas soluciones son clasificables dentro de dos tipologías diferentes: constructivas y concluyentes. Mientras la solución constructiva trata de aportar un posible recurso o procedimiento efectivo con el que superar el conflicto narrado, la solución concluyente es un final categórico que actúa de forma absoluta e indiscutible como si no existiera otra salida para el problema.

Una vez señalados los aspectos discursivos que se analizan dentro de las fotoanimaciones pasamos a enumerar los aspectos formales que se tienen en cuenta a la hora de estudiar las creaciones de los estudiantes, que serán básicamente dos: la fotografía y el montaje.

El análisis de la fotografía es relativo a la estética general del vídeo o, lo que es lo mismo, su dirección artística. Aquí trataremos de estudiar la mayor parte de las cuestiones de tipo formal como el cuidado de los espacios en los que se desarrolla la acción, el encuadre de los planos o el vestuario de los personajes. Con ello pretendemos averiguar la capacidad que tiene el alumnado de crear formas visuales con una naturaleza estética y expresiva (Eisner, 1995).

Por otro lado, en el análisis del montaje nos detendremos a observar si las fotoanimaciones realizadas por el alumnado utilizan como forma de enlazar los planos el montaje continuo o, por el contario, explotan otras alternativas distintas a la hora de articular los fotogramas entre sí. Esta elección ha sido desde el nacimiento del cine un dilema para sus creadores, y es que de ello depende que el flujo de atención de la imagen sea más fácil o más difícil de seguir por parte del espectador. De hecho, mientras el cine "comercial" se ha basado siempre en la idea de que "la transición de un plano a otro se realice de forma suave" (Bordwell y Thompson, 2002, p. 261) 
de manera que exista una continuidad espacio-temporal, las corrientes audiovisuales más relacionadas con el arte como el surrealismo francés o el cine soviético de los años 30 se han atrevido a romper estos esquemas para aprovechar, de una forma más original, las posibilidades gráficas y rítmicas del ensamblaje de los planos. En definitiva, si conseguimos descubrir la forma en la que los estudiantes articulan las imágenes en movimiento llegaremos también a saber el dominio que éstos tienen de este lenguaje específico, pues es improbable que alguien que no se mueve con soltura en la construcción de un discurso audiovisual emplee una disposición de los planos que se aleje del montaje continuo de las imágenes.

Una vez explicadas con detalle todas las cuestiones a analizar con respecto a las fotoanimaciones realizadas por los estudiantes procedemos a realizar un diagrama resumen de todos estos aspectos.

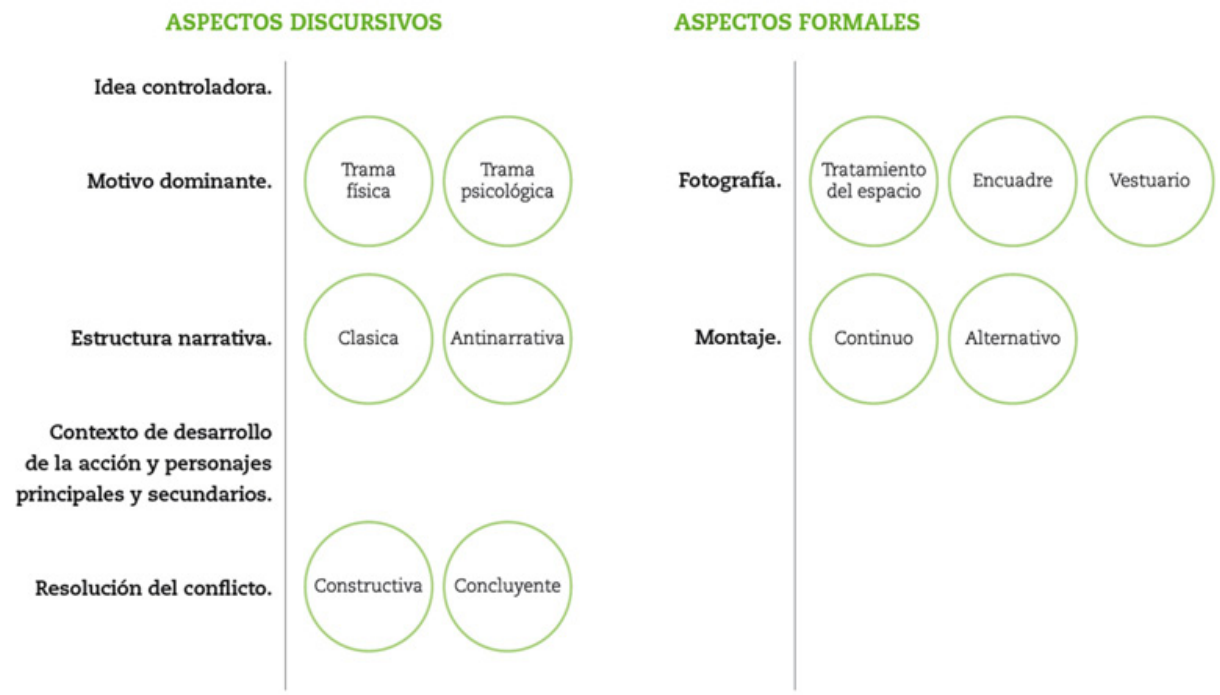

Figura 2. Diagrama resumen de todos los aspectos de análisis presentes en las fotoanimaciones realizadas por el alumnado

\section{Cuarta etapa: Contexto de investigación y puesta en marcha}

Sentadas las bases de esta investigación ha llegado el momento de pasar a describir la parte empírica de este estudio desarrollado en el I. E. S. Severo Ochoa de Granada.

Este instituto del distrito municipal granadino de La Chana es el único centro educativo de la ciudad y de su área periurbana que ofrece todos los bachilleratos existentes. Localizado en la zona noroccidental de la capital granadina, La Chana es un distrito de clase media trabajadora dividido en seis barriadas: Angustias, Chana, Victoria, Encina, Las Torres y Las Perlas. De estas seis zonas diferenciadas, tres están formadas por edificios de protección oficial y otras tres edificadas por constructoras privadas. Esto hace que dentro de la clase media nos encontremos con algunas parcelas consideradas de mayor estatus por parte de los propios vecinos. 
En definitiva, la realidad sociocultural del barrio y por extensión del I. E. S. Severo Ochoa, está conformada por un perfil de clase media, tanto alta como baja, que es mayoritario dentro de la estructura social de nuestro país. Por este motivo este centro educativo constituye un buen lugar en el que desarrollar un estudio de caso que podría ser extensivo a otras realidades actuales. Una vez seleccionado el centro nos ponemos en contacto con uno de sus profesores que, viendo las posibilidades educativas de la propuesta, decide incluir la experiencia como parte de los contenidos de la materia de Cultura Audiovisual en el mes de mayo de 2011. Esta asignatura es impartida a uno de los grupos de $1^{\circ}$ de Bachillerato del centro, y cuenta con 23 alumnos/as con edades comprendidas entre los 16 y los 20 años.

\subsection{Creación de fotoanimaciones}

Tras unas primeras sesiones en las que explicamos todos los conceptos necesarios para que los alumnos/as comiencen a trabajar en la creación de las fotoanimaciones, son ellos mismos quienes proceden a formar diferentes grupos de trabajo que no deben superar las cuatro personas. El resultado es la creación de cinco grupos de trabajo con tres componentes cada uno, dos grupos de dos componentes y uno de cuatro, la mayoría de ellos mixtos en cuanto al género. 8 agrupaciones que comenzarán a deliberar acerca del tema central a tratar en sus respectivas creaciones.

Una vez decidido ese tema, es el momento de comenzara trabajar en el desarrollo de la idea. Para ello, cada grupo elabora un pequeño storyboard o guión en el que plasman la acción que se desarrolla en sus historias.

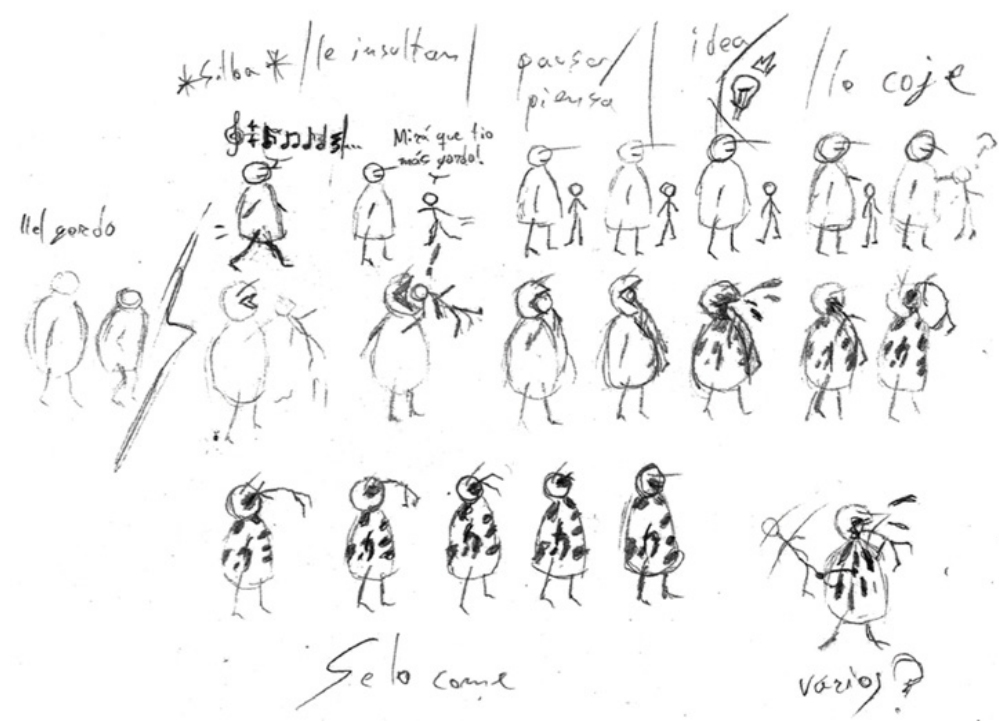

Figura 3. Storyboard elaborado por uno de los grupos participantes en el proyecto. Esta historia, a la que finalmente titularon "Gordito Caníbal" toca el tema de la burla hacia el más débil retratando una situación ficticia vivida por un niño con sobrepeso. Es importante señalar que la calidad artística de los storyboards no es un objetivo del proceso. Más bien al contrario, pretende utilizarse como una simple herramienta que ayude a los creadores a definir las acciones de su historia. 
La última etapa del proceso de creación es la toma de fotografías y la realización de la edición y el montaje de las mismas hasta llegar a la obtención de las obras finales, todas ellas recogidas en blog dedicado al proyecto que es posible consultar en la siguiente dirección: http://narrativasfotoanimadas.blogspot.com.es/

Como síntesis solo nos queda aclarar que los investigadores no intervinimos ni en la gestación de las ideas, ni en lo que se refiere a la creación de las obras audiovisuales. Por el contrario, nos encontramos en el aula como observadores y nuestra única intervención se produce al comienzo de la experiencia a la hora de explicar conceptos como el storyboard o el guión. Podríamos decir que una vez comenzado el proceso creativo nuestra intención no es guiar al alumnado hacia la consecución de un producto final de una calidad determinada, sino ser testigos de la forma en la que ellos mismos ejecutan sus creaciones.

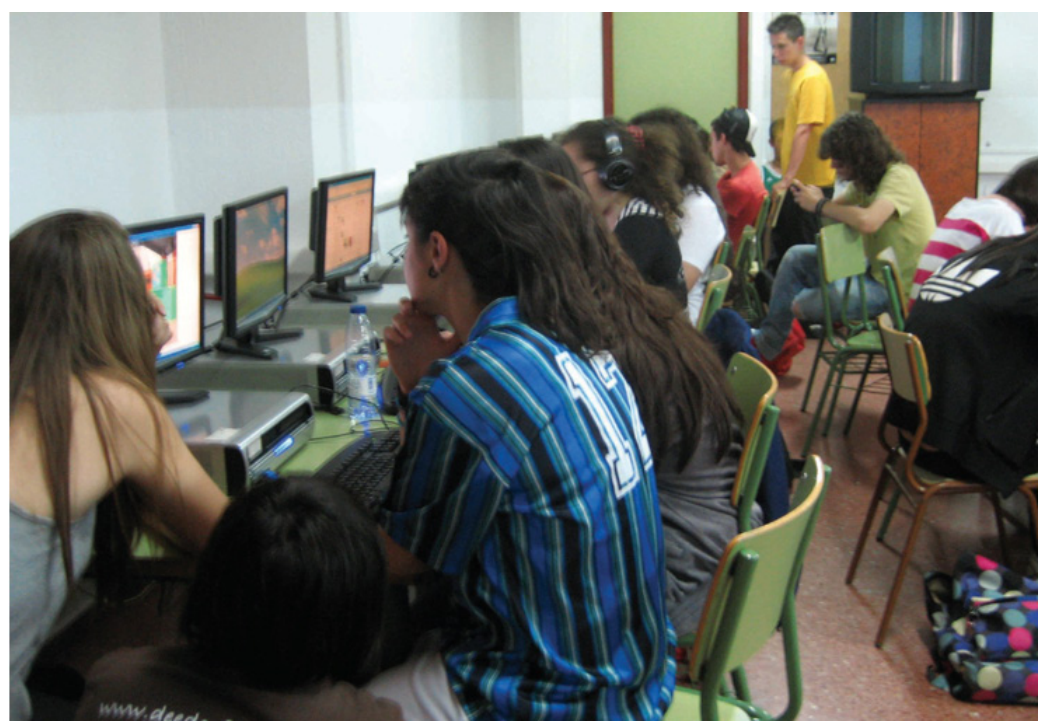

Figura 4. Grupo de alumnos/as de la asignatura de Cultura Audiovisual durante el proceso de creación de las fotoanimaciones.

\subsection{Análisis de fotoanimaciones: Resultados}

Una vez repasado todo el proceso de creación estamos en posición de poder analizar los resultados. Para ello, realizaremos un estudio pormenorizado de dos de las fotoanimaciones recogidas en base a las pautas de análisis expuestas en la tercera etapa de esta investigación.

La primera fotoanimación a la que nos referiremos se titula $N O$ al materialismo y en ella se trata un tema de interés general que se sale del contexto escolar. Su "idea controladora" es el papel del dinero en la sociedad y los componentes del grupo la tratan a través de una trama psicológica. Concretamente, nos narran una historia sobre la tentación que da lugar a una transformación final del personaje protagonista. 
En esta fotoanimación somos testigos de cómo una joven, que consigue de manera repentina mucha cantidad de dinero, hace cábalas sobre cómo gastarlo. En primer lugar piensa en una casa, después en un coche, más tarde en joyas y zapatos, hasta que todo ello desemboca en una estabilidad que la lleva a la búsqueda de una pareja y a la formación de una familia. El relato combina, por lo tanto, una reflexión acerca del dinero y una crítica hacia la estabilidad considerada como objetivo dentro de la sociedad de consumo. Esta joven, que se topa con la tentación de gastar su dinero de forma desmesurada gracias a su fácil obtención acaba por encontrarse también con un conflicto interior que la empuja hacia lo establecido, lo considerado como bueno en una "sociedad ideal". Finalmente, venciendo a la tentación, acaba por producirse en ella una transformación que la lleva a renunciar al dinero rechazando también con ello la comodidad de las convenciones sociales y abogando por su independencia y su libertad de decisión.

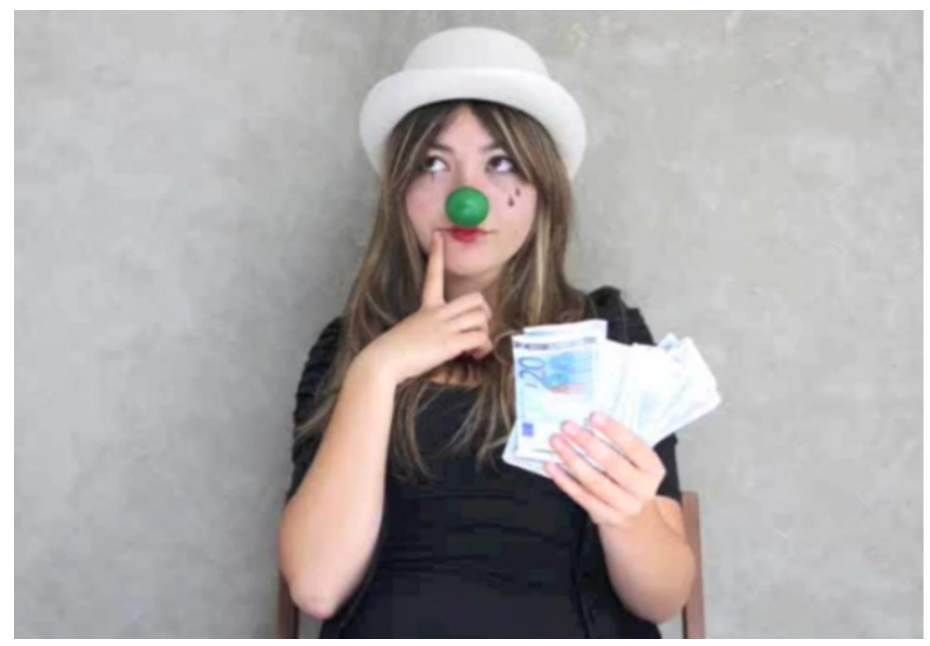

Figura 5. Fotograma de la fotoanimación "NO al materialismo" que es posible ver al completo en la dirección web http://narrativasfotoanimadas.blogspot.com.es/

Se trata de una narración con una estructura clásica. Observamos como a la protagonista se le presenta un conflicto que acaba por tener una resolución. Sin embargo, esta resolución se aleja del clásico "happy end" frecuente en la cinematografía comercial. Por el contrario, estos estudiantes rompen con los moldes para presentar su particular idea acerca de las opciones de elección que puede tener la juventud. Los protagonistas son ellos mismos, personificados en esa joven que renuncia a lo que comúnmente podríamos considerar el encuentro de la felicidad. En definitiva, en esta historia el conflicto se resuelve de forma constructiva, mostrando una opción de vida alternativa con respecto a lo que podríamos considerar un final feliz concluyente.

Por otro lado, por lo que respecta al análisis formal la imagen está claramente cuidada. Los estudiantes se han preocupado por buscar un espacio despejado y limpio, en el que imperan los colores claros, haciendo que el punto de atención de 
la imagen destaque sobre el resto. Vestuario y maquillaje están minuciosamente pensados, destacando dos expresivas lágrimas pintadas sobre el rostro de la joven que sirven también como cierre a la historia. Finalmente, el montaje utilizado se basa en la continuidad, dando coherencia temporal y espacial a la narración.

En la segunda fotoanimación que analizaremos, titulada ;Gordito Caníbal!, la idea controladora es la ridiculización o burla del más débil. Se trata de una trama psicológica que Tobias (2004) denomina trama del desvalido. En este tipo de historias el personaje principal se halla en desventaja representando la lucha entre el débil y el poderoso.

Los componentes de este grupo muestran en su historia a un adolescente con sobrepeso que se encuentra en varias ocasiones con diferentes individuos que lo insultan llamándolo "gordito". Tras vivir la situación repetidas veces el protagonista opta por acabar con el problema comiéndose al último que pretende ofenderle. Vemos, por lo tanto, como lo que en principio es una trama psicológica de desvalido se convierte en una trama física de venganza. El protagonista, que no ve otra solución para el problema, acaba eligiendo la violencia física extrema para resolverlo. No existe, por lo tanto, ninguna transformación, no se produce un aprendizaje y el personaje no evoluciona al final de la historia. Se trata, más bien, de una resolución concluyente del problema, que se presenta a falta de otra alternativa. Sin embargo, si se mira desde otro punto de vista, puede significar también la reafirmación del personaje protagonista, aceptándose a sí mismo tal y como es con las ventajas y desventajas que ello conlleva. Estos estudiantes, por lo tanto, se están afirmando también a sí mismos a través de esta historia, por no hablar de lo efectivo que resulta este final a ojos del espectador que lo observa como algo original y, sobretodo, sorpresivo.

En lo que respecta a la estructura narrativa de esta fotoanimación vemos, de nuevo, el uso del paradigma clásico que cuenta con la presencia de un principio, un medio y un fin.

Finalmente, en lo referente al análisis formal de este corto hay que señalar que los estudiantes se arriesgan al hacerlo dibujado y a pesar de que no entran demasiado en detalles, haciendo poco más que un bosquejo de los personajes, lo cierto es que las imágenes están perfectamente entrelazadas entre sí y resultan muy expresivas. Realizan un perfecto montaje continuo con la dificultad añadida de que las imágenes son dibujadas por ellos mismos. Se trata, por lo tanto, de una verdadera animación.

\section{Conclusiones}

Para terminar, y a modo de conclusiones, sólo cabe señalar que la experiencia y sus resultados han sido más que positivos, pues a través de una serie de discursos audiovisuales realizados por una serie de jóvenes hemos comprendido algo más acerca de la forma de pensar de la adolescencia. Podría decirse que hemos sido testigo de cómo los jóvenes que se encuentran en esta etapa del desarrollo se revelan contra la autoridad y lo establecido y colaboran entre sí en busca de una identidad propia que han conseguido defender a través de sus respectivos discursos. El audiovisual ha resultado ser, por lo tanto, una gran herramienta con la que acercarnos a la mente de estos jóvenes para poder descubrir un poco más acerca de cómo piensan y de cómo sienten. Estamos, por lo tanto, de acuerdo con la idea señalada por Coll, Selva 
y Solá en base a la cual a pesar de que pueda parecer que el audiovisual, por su condición de sistema expresivo, "se aleja del cientifismo únicamente ligado a la razón y a la lógica" (1995, pp.10-11) esto no significa que deba rechazarse todo esfuerzo intelectual o reflexivo con respecto a este medio, sino que es necesario comprender lo que éste tiene de discurso y lo que tiene de expresión para llegar a la obtención del conocimiento y la comprensión de los procesos a través del mismo.

\section{Referencias}

Aguirre, A. (1994). Estudios de etnopsicología y etnopsiquiatría. Barcelona: Marcombo.

Aristóteles (2009). La poética. García Yebra, V. (Trad.). Madrid: Gredos.

Arnett, J. J. (1995). Adolescents' uses of media for selfsocialization. Journal of Youth and Adolescence, 24 (5).

Aumont, J. (2004). Las teorías de los cineastas. La concepción del cine de los grandes directores. Barcelona: Paidós.

Bartolomé, A. (2008). Vídeo digital y educación. Madrid: Síntesis.

Bordwell, D. \& Thompson, K. (1995). El arte cinematográfico. Barcelona: Paidós Comunicación 68 Cine.

Coll, M., Selva, M. \& Solá, A. (1995). El filme como documento de trabajo escolar. Cuadernos de pedagogía. 242: 10-11.

Decaigny, T. (1978). La tecnología aplicada a la educación. Un nuevo enfoque de los medios audiovisuales. Buenos Aires: Ateneo.

De la Llave Cuevas, J. (2009). Pensando la sociedad desde el cine. En Sebastián Lozano, J. (Coord.) El audiovisual y la educación para el desarrollo. Del entretenimiento a la participación. Valencia: Fundación Mainel.

Eisner, E. W. (1995). Educar la visión artística. Barcelona: Paidós.

Erikson, E. (1992). Identidad: juventud y crisis. Madrid: Taurus.

Escaño González, C. (2002). Ejemplificación de la posmodernidad: Creatividad plástica y Kitsch audiovisual. Sevilla: C.E.G.

Ferrés, J. (1996). Educar en la cultura del espectáculo. Barcelona: Paidós.

Field, S. (1995). El libro del guión. Fundamentos para la escritura de guiones. Madrid: Plot.

Giroux, H. A. (2003). Cine y entretenimiento. Elementos para una crítica política del filme. Barcelona: Paidós.

González Almagro, I. (1994): Socialización del adolescente. En Aguirre, A. Psicología de la adolescencia. Barcelona: Marcombo.

Gubern, R. (1974). Mensajes icónicos en la cultura de masas. Barcelona: Lumen.

Hopkins, J. R. (1987). Adolescencia. Años de transición. Madrid: Pirámide.

Huertas, A. (2002). La audiencia investigada. Barcelona: Gedisa.

Kett, J. F. (1977). Rites od pasaje: Adolescence in America 1970 to the present. New York: Wiley.

Kohlberg, L. (1992). Psicología del desarrollo moral. Bilbao: Descléé de Brouwer. 
Loevinger, J. (1990). Ego development in adolescente. En Mauss, R. y Porton H. (Eds.) Adolescent behavior and society. A book of readings. New York: McGraw Hill.

Maeso Rubio, F. (2008). La TV y la educación en valores. Comunicar. Revista científica de Educomunicación, ${ }^{\mathrm{o}} 31$, v. XVI.

Martínez Vázquez, V. (2002). Arte y educación artística infantil en los debates de las postmodernidad: géneros, miradas y emociones. Arte, Individuo y Sociedad. $\mathrm{n}^{\mathrm{o}}$ 14, Anejo I.

McKee, R. (2004). El guión. Barcelona: Alba.

Mitry, J. (1978). Estética y psicología del cine. Madrid: SigloXX.

Montero Díaz, J. (2009). El audiovisual, la educación para el desarrollo y el entretenimiento. En Sebastián Lozano, J. (Coord.) El audiovisual y la educación para el desarrollo. Del entretenimiento a la participación. Valencia: Fundación Mainel.

Montero Rivero, Y. (2006). Televisión, valores y adolescencia. Barcelona, España: Gedisa.

Padilla Novoa, M. (2002). Técnicas de persuasión en la televisión. Madrid: Ediciones del Laberinto.

Palacios, J. (1991). ¿Qué es la adolescencia? En Palacios, J., Marchesi, A. y Coll, C. (Coords.). Desarrollo psicológico y educación (Vol.1). Madrid: Alianza Editorial.

Rocheblave-Spenlé, A. M. (1975). El adolescente y su mundo. Barcelona: Herder.

Rocher, G. (1985): Introducción a la sociología general. Barcelona: Herder.

Roldán Ramírez, J. (2003). El discreto encanto de los tiempos modernos. En Marín Viadel, R. (Coord.) Didáctica de la educación artística. Madrid: Pearson.

Sánchez Noriega, J. L. (1997). Crítica de la seducción mediática. Madrid: Tecnos.

Tobias, R. B. (2004). El guión y la trama. Fundamentos de la escritura dramática audiovisual. Madrid: Ediciones Internacionales Universitarias.

Vogler, C. (2002). El viaje del escritor. Barcelona: Robinbook.

\section{Notas}

1. Recordemos que, como ya señalamos en la introducción, una fotoanimación es, en el contexto de esta investigación, una narración audiovisual realizada con la técnica del stop motion que tiene como fundamento narrativo la denuncia y proposición de un cambio y su intención final es que los estudiantes se vean comprometidos a reflexionar acerca de aquellas cuestiones que les preocupan y afectan de forma directa 